\title{
O PROCESSO DE CUIDAR DA PESSOA QUE SOFREU QUEIMADURAS: SIGNIFICADO CULTURAL ATRIBUÍDO POR FAMILIARES
}

\author{
THE PROCESS OF DELIVERING CARE TO A BURNED PERSON: CULTURAL \\ MEANING ATTRIBUTED BY RELATIVES
}

\section{EL PROCESO DE CUIDAR DE PERSONAS QUE SUFRIERON QUEMADURA: SIGNIFICADO CULTURAL ATRIBUIDO POR FAMILIARES}

Lidia Aparecida Rossi*

Rossi LA. O processo de cuidar da pessoa que sofreu queimaduras: significado cultural atribuido por familiares. Rev Esc Enferm USP 2001; 35(4): 336-45.

\section{RESUMO}

Os objetivos deste estudo etnográfico foram identificar o significado cultural atribuido por familiares à participação no processo de cuidar da pessoa ultima de queimadura; identificar as estratégias de cuidado que os familiares focalizam frente à participação no cuidado. Os dados foram coletados mediante entrevistas semi-estruturadas com 25 familiares de clientes que sofreram queimaduras, admitidos em uma Unidade de Queimados e observações participantes. Os resultados mostram que o significado cultural atribuido por familiares de pessoas vitimas queimaduras ao processo de cuidar tem duas dimensões: a fisica e a moral e gera principalmente medo.

PALAVRAS-CHAVE: Queimaduras. Cultura. Cuidado.

\section{ABSTRACT}

This study aimed at investigating the cultural meanings attributed by relatives to their participation in the process of delivering care to burned people; identifying the care strategies focused on by relatives during their participation in the care process. Data were collected by means of semi-structured interviews with 25 relatives of burned patients admitted in a Unit for Burned and by participant observation. The results of this study show that the perspective of giving care to a burned person has two dimensions: a physical dimension and a moral one; and generates mainly fear.

KEYWORDS: Burns. Culture. Caring.

\section{RESUMEN}

Los objetivos fueron investigar los significados culturales atribuidos por familiares a la participación en el proceso de cuidar de personas victimas de quemadura; identificar las estratégias que los familiares enfocan en su participación en el cuidado. Los datos fueron colectados a través de entrevistas semi-estructuradas con 25 familiares de clientes quemados admitidos en una Unidad de Quemados y a través de observaciones participantes realizadas durante el periodo de visitas y en reuniones con familiares de clientes. Los resultados de este estudio muestran que la perspectiva de cuidar de una persona que sufrió una quemadura tiene dos dimensiones: la física y la moral, y genera principalmente miedo.

PALABRAS-CLAVE: Quemaduras. Cultura. Cuidado.

Enfermeira, Profa Associada junto ao Departamento de Enfermagem Geral e Especializada Escola de Enfermagem de Ribeirão Preto SP. Email: rizzardo@glete.eerp.usp.br 


\section{INTRODUÇÃO}

A atitude da família do cliente que sofreu uma queimadura em relação a sua imagem corporal é muito importante. Em um estudo sobre as representações sociais que os familiares de clientes vítimas de queimaduras atribuem às sequelas desse tipo de trauma, concluímos que, na fase mediata da queimadura, grande parte dos familiares de clientes que sofreram trauma térmico desconhece as conseqüências da queimadura. Entretanto, mesmo desconhecendo, os familiares têm uma representação da queimadura, que é aquela do trauma que deixa marcas e cicatrizes; deformidades essas que causam reações nas pessoas no convivio social (1). A partir da realização deste estudo (1), considerando a importância da participação dos familiares para a recuperação e para a reintegração na sociedade de pessoas que sofreram queimaduras, foi organizado um grupo de discussão entre familiares de clientes que sofreram queimaduras e a equipe de profissionais que atua na Unidade de Queimados do Hospital das Clínicas da Faculdade de Medicina de Ribeirão Preto (HCFMRP), com o objetivo de preparar essas pessoas para assistir o cliente após a alta hospitalar.

Embora os familiares sejam freqüentemente os principais fornecedores de suporte social, eles também podem se sentir sufocados pelas necessidades emocionais da pessoa desfigurada (2). O sucesso da reabilitação pode ser influenciado de forma crucial pela habilidade com que a equipe melhora a angustia psicológica dos familiares e promove meios para alcançar isso, por exemplo, por meio de reuniões de grupos. Nessas reuniões, os familiares podem se sentir apoiados pelos outros que vivenciam problemas semelhantes, aprendendo com o relato das outras pessoas (3).

Embora a importância da atuação dos familiares seja reconhecida, há relativamente poucas pesquisas nessa área, o que é uma surpresa considerando a importância do papel da família (4). Em uma investigação qualitativa sobre as preocupações e necessidades de familiares de clientes que sofreram queimaduras. Os familiares manifestaram preocupação com as necessidades fisicas e psicológicas dos clientes ${ }^{(5)}$.

Encontramos publicações em que foi enfocada a importância do cuidado centrado na família em unidade de queimados onde tradicionalmente as visitas são restritas (6) Ainda no que tange a alta hospitalar desses clientes, outros autores enfocaram o processo de reabilitação $\left({ }^{740}\right)$. Nesse aspecto, tem sido estudada, prioritariamente, a mobilidade fisica dos clientes que sofreram queimaduras, visando à independência na realização de atividades diárias $(7,8)$. Entretanto, não encontramos estudos que abordassem os significados culturais atribuídos à queimadura, principalmente no que se refere à participação da família no processo de cuidar.

O conceito de familia tem sido definido de diferentes formas por uma variedade de teóricos. Neste estudo, consideramos a familia a partir da perspectiva do cliente e das pessoas próximas, assim, os familiares indicaram quais eram as pessoas consideradas como membros do sistema familiar. Portanto, entendemos por família não somente as pessoas que estão unidas por laços de consangüinidade ou por casamento civil ou religioso, mas as que estão envolvidas emocionalmente ou vivem próximas.

Têm sido utilizados três tipos de abordagens nas teorias sobre famílias: a orientação tradicional, a transacional e a não tradicional. Neste estudo, utilizamos a abordagem não tradicional. Esta abordagem implica na necessidade de conhecer as perspectivas dos familiares e é orientada pela abordagem sistêmica. Acredita-se que há realidades independentes do observador, que são infinitamente múltiplas e podem ser percebidas pela interação. Não há uma única realidade ou verdade que é mais correta que outra. Esta crença implica na consideração, pelo profissional de saúde, das crenças, idéias e experiências da familia. Os pré-julgamentos sobre o certo, verdadeiro ou mais correto são excluídos ${ }^{(11)}$.

Uma vez que a família tem papel relevante no processo de reabilitação da pessoa vítima de queimaduras, o foco de atenção deste estudo é a cultura dessas pessoas no que tange a esses aspectos. Adotamos neste estudo a definição de cultura na qual cultura é entendida como um sistema de significados aprendidos, comunicados por meio da linguagem natural e de outros sistemas de símbolos que têm funções representativas, diretivas e afetivas, e capacidade de criar entidades culturais e sentidos particulares da realidade (12).

Assim, considerando importante conhecer a cultura de um grupo de familiares de clientes que sofreram queimaduras, realizamos um estudo etnográfico e utilizamos para interpretar os dados o Modelo Explicativo para estudar a experiência da doença (13). Com base nessa perspectiva, o conceito de doença (disease - processo de doença) ${ }^{2}$ está centrado nas mudanças fisicas de estrutura e funcionamento

Na literatura, há diferentes traduções para o português para as palavras disease e illness. Na língua inglesa, a palavra illness designa o estado de estar genericamente doente, a palavra disease possui um significado especifico, refere-se à alteração na estrutura ou funcionamento do corpo ou de um órgão ou de partes do corpo (14). Há autores que optaram por traduzir a palavra illness por enfermidade (15) e outros, por distúrbio(16), já a palavra disease tem sido traduzida por doença (15,16) . Neste estudo, optamos por utilizar os termos processo de doença ou doença ao focalizar o significado de disease, e pelo termo experiência da doença para focalizar o significado de illness (17). 
do organismo, sob o ponto de vista do profissional de saúde, enquanto o conceito de experiência da doença (illness - experiência da doença) está relacionado a um modelo conceitual mais abrangente, utilizado pelo doente e familiar para explicar o infortúnio pelo qual estão passando. Sendo assim, o médico diagnostica o processo da doença e os indivíduos focalizam a experiência da doença. Os familiares também expressam a experiência da doença (illness) vivenciada por eles. A experiência da doença (illness) envolve um processo de atenção, percepção, resposta afetiva direta, cognitiva e atribuição de valor à manifestação da doença como um processo; resulta de comunicação e interação interpessoal no contexto da família e de uma rede de trocas de informações. O processo de doença (disease) afeta um único indivíduo, mas a experiência da doença (illness), muito freqüentemente, afetará todos os outros que convivem com essa pessoa, como por exemplo, sua familia, seus amigos, seus colegas de trabalho. $O$ processo de doença tem caracteristicas que são independentes do ambiente, apresenta uma evolução típica, já a experiência da doença tem que ser compreendida em um contexto específico de normas e significados simbólicos e de interação social (13).

Assim, os objetivos deste estudo foram: identificar os significados culturais atribuídos por familiares à participação no processo de cuidar da pessoa que sofreu queimadura e as estratégias de cuidados que os familiares focalizam frente à participação no cuidado. Para o alcance dos objetivos descritos realizamos um estudo etnográfico, cuja metodologia está descrita a seguir.

\section{METODOLOGIA}

Este estudo etnográfico foi desenvolvido considerando as seguintes fases: escolha da situação social, trabalho de campo e análise dos dados. A situação social selecionada para o desenvolvimento desse estudo focalizou a participação da família de clientes vitimas de queimaduras admitidos na Unidade de Queimados do HCFMRP em reuniões e durante as visitas aos clientes no hospital no processo de cuidar. Assim, os sujeitos foram os familiares de clientes que sofreram queimaduras admitidos nesta Unidade.

Após a obtenção da aprovação pelo Comitê de Ética e Pesquisa da instituição em estudo, em janeiro de 2000, foi iniciado o trabalho de campo. Foram utilizadas no processo de coleta de dados a observação participante e a entrevista. A freqüência de contatos com familiares variou de acordo com a gravidade do caso do cliente e a necessidade de apoio dos familiares. Familiares de clientes mais graves comparecem mais vezes ao, hospital para visitas e participação de reuniões. Após cada interação corn os familiares, eram realizadas as notas de campo. Foram observadas todas as atividades realizadas por essas pessoas durante a permanência nesta Unidade.

$\mathrm{Na}$ escolha dos sujeitos, procuramos identificar os chamados informantes-chaves, ou seja, os familiares ou as pessoas próximas que se dispuseram a fornecer as informações e que participariam do cuidado após a alta hospitalar. Assim, foram considerados como sujeitos os familiares ou pessoas próximas de clientes que sofreram queimaduras, acima de 21 anos, que demonstravam ter maior vínculo com ele. No período de janeiro a setembro de 2000, procuramos entrevistar todos os familiares que atendiam esses requisitos, mediante a assinatura do termo de consentimento.

As entrevistas foram orientadas pelas seguintes questões iniciais: - Como é para você ter um parente (ou um amigo) que sofreu uma queimadura? Como você se sente com relação a situação do seu parente (ou amigo)? O que vai acontecer quando seu parente (ou amigo) retornar para casa? O que você pretende fazer quando ele retornar para casa? Como você acha que poderá ajudá-lo? Os dados da observação participante e entrevistas informais foram registrados com papel e lápis, e quando possivel, registrados diretamente no computador. Os dados obtidos nas entrevistas formais foram registrados com gravador e, posteriormente, as transcrições das fitas foram digitadas no computador.

No processo de análise, consideramos as seguintes fases inter-relacionadas, a saber, redução dos dados, demonstração dos dados e delineamento das conclusões e verificação. $O$ processo de redução dos dados foi iniciado com o desenvolvimento do estudo. Inicialmente, buscamos extrair dos dados, idéias que se constituíram em conceitos importantes mediante a realização de leitura cuidadosa das informações a medida em que eram coletadas e organizadas. A partir desse processo, os dados foram codificados, ou seja, informações semelhantes foram agrupadas e rotuladas constituindo unidades de significados que variaram de acordo com os tipos de dados. Cada uma dessas unidades foi explicada e conceituada (18).

Para que pudéssemos checar os códigos e as categorias criadas, foi solicitado a três outras pesquisadores experientes em estudos dessa natureza, que realizassem o mesmo procedimento com registros de dados selecionados mediante sorteio (em torno de 10 páginas cada registro, entre entrevistas e diários de campo) (18). Apenas uma pesquisadora fez sugestões que foram incluídas na análise dos dados. A partir desse procedimento não foram constados outros códigos, apenas um foi renomeado.

A partir desses primeiros códigos, os dados foram novamente analisados com o objetivo de verificar a freqüência em que essas unidades de 
significado são apresentadas e construir as categorias. Após esse processo, os códigos similares deram origem as categorias. Identificamos, dessa forma, o tema cultural, ou seja, o significado cultural atribuído ao processo de cuidar comum a todas as categorias. Foram identificadas três categorias: 1) 0 estigma da queimadura: o mundo do queimado é um mundo que só quem está dentro sabe o que é; 2) Ser uma "boa mãe" e conviver com a culpa, com o medo e com o desconhecimento sobre o cuidado, e 3) A participação da familia no processo de cuidar da pessoa que sofreu queimaduras: dar apoio moral e fazer tudo o que estiver ao alcance. $O$ tema cultural que foi identificado neste estudo foi: $\mathrm{O}$ estigma da queimadura e o processo de cuidar -o medo num mundo que só quem está dentro sabe o que é.

\section{RESULTADOS E DISCUSSÃO}

A Unidade de Queimados, onde este estudo foi realizado, está localizada no quarto andar da Unidade de Emergência do HCFMRP e foi ativada em 1982. No período em que os dados foram coletados, as visitas de familiares aos clientes internados na Unidade de Queimados eram programadas para dois dias da semana para clientes adultos e, diariamente, para as crianças. Atualmente, as visitas estão programadas para todos os dias da semana para todos os clientes. Durante o período destinado a visitas, foi possivel notar que muitas pessoas que visitam os clientes buscam satisfazer alguma curiosidade, outras, satisfazer uma necessidade pessoal de ajudar o outro, algumas vezes expressa como cumprimento de uma formalidade perante um outro membro da familia ou perante o próprio cliente. Alguns relatam que, nesse momento, procuram "fornecer um apoio" ou "dar uma força".

Quando iniciamos o trabalho de campo, a cada quinze dias aconteciam reuniões com familiares em um dia fixo da semana, posteriormente, essas reuniões passaram a ser realizadas semanalmente. Participam dessas reuniões os enfermeiros, a fisioterapeuta, uma assistente social e uma psicóloga. Nessas reuniões os familiares são estimulados a falar sobre seus sentimentos, dúvidas e inquietações.

Os profissionais presentes à reunião esclarecem esses aspectos quando surgem; tentam diminuir a ansiedade dos familiares e fornecem indicações sobre como enfrentar o problema. Geralmente, essas explicações são baseadas nos modelos explicativos dos profissionais e não dos familiares.

Além das observações participantes, foram entrevistados 25 familiares de clientes que sofreram queimaduras. Na Tabela 1, são apresentadas as características dos familiares de clientes, que foram entrevistados formalmente neste estudo, distribuídos de acordo com o grau de parentesco com a pessoa que sofreu queimaduras, o grau de instrução e a renda familiar.

Tabela 1- Distribuição dos familiares entrevistados formalmente, segundo o grau de parentesco com a pessoa que sofreu queimaduras, grau de instrução e renda familiar. Ribeirão Preto, SP 2000.

\begin{tabular}{|c|c|c|c|c|c|c|}
\hline \multirow[b]{2}{*}{$\begin{array}{c}\text { Grau de } \\
\text { parentesco }\end{array}$} & \multicolumn{6}{|c|}{ Renda Familiar } \\
\hline & $\begin{array}{l}\text { Grau de } \\
\text { instrução }\end{array}$ & $\begin{array}{c}\text { até } \\
130,00 \mathrm{R} \$\end{array}$ & $\begin{array}{c}130,00 \mathrm{a} \\
500,00 \mathrm{R} \$\end{array}$ & $\begin{array}{c}500,00 \mathrm{a} \\
1000,00 \mathrm{R} \$\end{array}$ & $1000,00 \mathrm{R} \$$ & Total \\
\hline Mãe & $\begin{array}{l}\text { Analfabeto } \\
1^{\circ} \text { grau } \\
2^{\circ} \text { grau } \\
\text { Universitário }\end{array}$ & $\begin{array}{l}1 \\
2\end{array}$ & $\begin{array}{l}6 \\
1\end{array}$ & $\begin{array}{l}3 \\
2\end{array}$ & 1 & $\begin{array}{r}1 \\
11 \\
3 \\
1\end{array}$ \\
\hline Esposa & $\begin{array}{l}\text { Analfabeto } \\
1^{\circ} \text { grau } \\
2^{\circ} \text { grau } \\
\text { Universitário }\end{array}$ & & 2 & 2 & & 4 \\
\hline Irmã & $\begin{array}{c}\text { Analfabeto } \\
1^{\circ} \text { grau } \\
2^{\circ} \text { grau } \\
\text { Universitário }\end{array}$ & 1 & 2 & 1 & 1 & $\begin{array}{l}4 \\
1\end{array}$ \\
\hline Total & & 4 & 11 & 8 & 2 & 25 \\
\hline
\end{tabular}

Os dados apresentados na Tabela 1 se referem a entrevistas formais realizadas com os informanteschaves, entretanto, outros membros da família de clientes participaram do estudo. Nesses casos, os dados foram coletados durante as observações participantes e em reuniões realizadas na Unidade e registrados no diário de campo. Embora fizessem parte do sistema familiar, esses familiares não estavam diretamente envolvidos com o cuidado e não participaram das entrevistas formais. Outras pessoas 
pertencentes ao sistema familiar foram convidadas a participar, mas não se dispuseram. Conforme pode ser ainda observado na Tabela 1, as mães constituíram as pessoas mais próximas dos clientes (16), seguidas pelas irmãs ${ }^{(5)}$.
A caracterização dos clientes vítimas de queimadura, que correspondem aos 25 familiares que participaram das entrevistas, pode ser observada na Tabela 2, no que se refere à idade, ao tipo de acidente e ao sexo.

Tabela 2 - Distribuição dos clientes que sofreram queimaduras, segundo o sexo, o tipo de acidente a faixa etária. Ribeirão Preto, SP 2000.

\begin{tabular}{llccc}
\hline \multirow{2}{*}{ Sexo } & Tipo de Acidente & \multicolumn{2}{c}{ Faixa etária } \\
\cline { 2 - 5 } & & $0-10$ & $10-21$ & $>21$ \\
\hline Feminino & Doméstico & 4 & 1 & 5 \\
& Trabalho & & 1 & 1 \\
& Tentativa de suicídio & & 3 & 2 \\
\hline Masculino & Doméstico & 6 & 5 & 5 \\
& Trabalho & & & 5 \\
\hline Total & Tentativa de suicídio & & 7 & 8
\end{tabular}

Na Tabela 2, observa-se que 17 clientes tinham menos que 21 anos, o que pode justificar o maior número de mães envolvidas no processo de cuidar, possivelmente, em razão do forte vínculo entre mãe e filho. Como pode ser também observado, na Tabela 1, todas as pessoas que participaram das entrevistas formais, eram mulheres, o que está de acordo com a cultura, em que o cuidado a pessoas com algum problema de saúde constitui uma tarefa feminina. Em um estudo sobre as práticas de atenção à saúde no cotidiano das famílias, as mães também foram identificadas como asprovedoras e agentes de cuidados (19)

Tanto por meio dos dados coletados mediante as entrevistas formais, como nas observações participantes, durante o processo de análise, os aspectos que chamaram a atenção foram os sentimentos e comportamentos reportados pelos familiares frente às alterações das estruturas e função do corpo. Esses e outros aspectos são apresentados e discutidos, a seguir, considerando as categorias e o tema cultural identificados.

1. 0 estigma da queimadura: o queimado é um mundo que só quem está dentro sabe o que é

Nessa categoria, foram agrupados os sentimentos manifestados pelos familiares relacionados com o processo de cuidar. Os familiares relataram sentimentos de medo, sofrimento, vergonha, culpa, resignação, afeto e felicidade pela situação de seu parente.

Entre os sentimentos manifestados, o medo foi reportado por 11 dos 25 familiares. As dimensões de medo reportadas pelos familiares foram: as reações das outras pessoas quando observam o cliente, de não saber como cuidar, de machucar ao tocar o cliente, das reações do cliente ao enfrentar o mundo fora do hospital, das suas próprias reações e da perda do trabalho. Os depoimentos a seguir exemplificam os sentimentos de medo do familiar relacionados com o olhar das outras pessoas, possivelmente, pela própria dificuldade de lidar com o problema:

...eu só estou com medo dos meus vizinhos falarem alguma coisa... (...) Porque eles falam, e eu tenho medo deles falarem do rosto dela, só isso. (familiar 1, mãe).

Nota-se nos depoimentos a dimensão do medo relacionada às reações dos outros diante da percepção das seqüelas das queimaduras e da expectativa de que essas reações possam ser agressivas e o sofrimento do familiar:

...eu acho que eu sofro do mesmo jeito que ela está sofrendo... Eu acho que ela vai sofrer muito, agora ela vai ver que não pode mais se arrumar do jeito que ela se arrumava, ela vai sentir que os outros estão destratando ela... (familiar 7, irmã).

O sofrimento está estreitamente relacionado com o estigma da queimadura. O estigma pode começar com a própria reação da sociedade, quando diante de um determinado problema de saúde a pessoa passa a ser rotulada, evitada, ridicularizada e degradada pelas pessoas próximas, que não necessariamente são da família. Entretanto, diante das regras, legitimadas pela sociedade, eventualmente, a familia e os próprios clientes antecipam a reação dos outros (13), como pode ser observado no exemplo a seguir: 
__Nossa senhora! eu fico até com vergonha, fico o dia inteirinho socada dentro de casa, nem saio na rua... Agora as minhas vizinhas vão até a minha casa para perguntar como que está o rosto e a pele dela. Eu sinto que parece que elas querem que o rosto da criança fique manchado. Elas também querem vir até o hospital para visitar só de curiosidade, para contar na rua, como que está o rosto dela (familiar 1, mãe).

As pessoas sentem vergonha em função do significado cultural da doença expresso nas reações das outras pessoas. E importante salientar que os sistemas de significados que envolvem a experiência da doença são também construídos a partir dessas reações ${ }^{(13)}$.

No relato a seguir, observa-se também o estigma que acompanha a seqüela da queimadura em nossa cultura:

.., eu vou ter que vir de ônibus (no dia do retorno ao hospital), eu não queria trazer ela de ônibus porque todo mundo fica olhando. Tem pessoa que é curiosa, mesmo dentro do ônibus, a gente entra, todo mundo sai de perto, é sempre assim. (familiar 1, mãe).

Nesse caso, os sentimentos dessa mãe podem influenciar o próprio tratamento da filha, por exemplo não comparecendo ao hospital, evitando sair de casa, ou mudando os hábitos da vida diária na tentativa de esconder a criança, que, por ter apenas um ano de idade, não pode interferir. No caso da queimadura, o que está mais proeminente na experiência da doença, para clientes e familiares, é a mudança na aparência, aquilo que é visivel aos olhos das outras pessoas. Os modelos explicativos são então construídos com base nesse aspecto, influenciado pelas crenças, por toda uma rede de significados culturais(13). No depoimento a seguir, a mãe compara a situação da queimadura com uma outra de experiência de adoecimento - a de ter um câncer:

O queimado é um mundo que só quem está dentro sabe o que é, é como deve ser o mundo do câncer (familiar 17, mãe).

O câncer é considerado, em nossa sociedade, como alguma coisa injusta, imprevisivel, que aponta as nossas falhas no controle sobre a morte e sobre a imagem, e nos confronta com uma questão que não tem resposta do ponto de vista científico: Por que eu? (13) O câncer tem sido descrito como algo cruel, um predador imoral, um inimigo, uma doença misteriosa que envolve o eu como um todo e está associada à desesperança e ao medo da morte(20).
Assim como a queimadura, o câncer nos faz sentir sem controle sobre nós mesmos e sobre os outros. A queimadura significa a perda de alguma coisa, significa a morte de uma pessoa que tinha uma determinada aparência e surgindo, em poucos instantes, uma : outra que se mostra de uma outra forma, desfigurada. A falta de controle nos faz sentir vulneráveis e nos leva a não aceitar e até a desejar modificar a situação, como pode ser observado nos exemplos a seguir:

Eu pergunto até hoje, por que a minha filha? Elas estavam em duas, não que eu queria que a outra queimasse, mas por que a minha filha de novo? Ela já tinha quebrado o braço... Na bíblia até diz que a gente pode sofrer acidente, mas por que ela? (familiar 29, mãe).

A doença pode estar localizada nos tecidos de um único individuo, mas a experiência da doença incorporará todo o seu circulo social, sua família, seus amigos, as pessoas próximas, seu trabalho. Os sentimentos de medo e de desmoralização raramente estarão restritos ao cliente (13)

"Uma mudança em um membro afeta todos os outros membros de uma família(21). Quando consideramos a família como um sistema, a sua análise implica em aceitar que os fenômenos e conceitos são organizados e interagem com interdependência e integração das partes e elementos. Assim, quando um membro de uma família é afetado, como por exemplo, no caso de uma queimadura, ocorrerão mudanças na organização e funcionamento do sistema familiar como um todo.

Vinte e dois, dos 25 familiares entrevistados, relataram sentimentos de tristeza, revolta, vergonha, culpa, negação, resignação e/ou ansiedade. Esses sentimentos estão relacionados com o estigma da queimadura e podem dificultar mais ainda a participação do familiar no cuidado e na própria convivência do cliente ao retornar para casa:

\section{-.. na véspera eu tinha queimado formigas com álcool e no outro dia, ela fez a mesma coisa e se queimou. Eu fui o professor. Eu queimei essa menina, eu sou o culpado... Eu fico pensando, ela nunca vai poder namorar... (familiar 27, pai).}

A culpa e a vergonha têm sido consideradas "guardiãs das normas da sociedade e são as fundações da ordem moral, em um mundo em que os indivíduos não buscariam objetivos desinteressados" (22). Assim, a culpa, como um tipo de sanção, é associada com a mudança individual em relação ao que a sociedade legitima como bom. A vergonha está associada com as sociedades que, da mesma forma, mediante normas 
e crenças legitimadas, subordinam a pessoa a um conjunto de hierarquias, demonstrando que é preocupada com a manutenção das coisas como estão e não com a mudança (22).

Os familiares de clientes que sofreram queimaduras se sentem culpados, não só porque, de alguma forma, podem ter contribuído para a ocorrência do acidente que vitimou o seu parente, mas porque infringiram uma regra legitimada socialmente, e se sentem envergonhados da mesma forma, pois impõem aos outros a convivência com uma pessoa que foge aos padrões culturais aceitos.

Outros sentimentos apresentados foram amor e felicidade em ter o cliente de volta em casa. Das três pessoas que relataram esses sentimentos, duas identificaram formas de participação no cuidado, como por exemplo, ser capaz de ouvir, de acalmar a pessoa, de fazer cuidados básicos, de apoiar e estimular a pessoa:

_A familia toda está muito bem preparada para recebê-lo. Estamos muito felizes. Eu acho que o cuidado é assim, tem o cuidado físico e o moral. Eu sou apta para fazer o cuidado dele, desde o curativo até a força para ele ficar bem psicologicamente, tem que conversar muito... O cuidado moral é assim, porque a pessoa fica para baixo, na cabeça dele fica uma confusão... Então, a gente tenta mostrar que a realidade é outra, não a que ele guardou no subconsciente dele... Vou ouvir, acalmar e fazer os cuidados básicos que precisar... (familiar 20, mãe).

Assim, para os familiares o cuidado tem uma dimensão física e outra moral. O cuidado físico está relacionado com o cuidado com as cicatrizes, com as lesões e o cuidado moral está relacionada com a assistência frente à reação emocional dos clientes relacionadas às mudanças corporais.

2. Ser uma "boa mãe" e conviver com a culpa, com o medo e com o desconhecimento sobre o cuidado.

Nessa categoria, reunimos os depoimentos em que os familiares abordam os sentimentos de culpa, a expectativa com o papel de mãe, com o desconhecimento sobre o cuidado e com os receios de realizar esse cuidado e, nesse aspecto, o medo e a sensação de estar perdida foram os sentimentos apontados mais freqüentemente.

Nove, dos 25 familiares de clientes, relataram que se sentem perdidos e não sabem o que fazer para ajudar.

Eu não sei direito o que fazer para ajudar, porque estou muito abalada, estou completamente perdida... (familiar - 15, mãe).
A minha mãe me diz que eu não fui uma boa mãe (Nesse momento, a mãe - familiar 25 apresenta os olhos marejados de lágrimas).

Nesse último depoimento, a mãe expressa toda a culpa e sofrimento por não ter sido uma "boa mãe". Há um sofrimento moral por não ter cumprido o seu papel aos olhos da sua família e da sociedade. Ser uma "boa mãe" e ser responsável pela educação e proteção dos filhos parece ser uma atribuição das mães em nossa cultura. Isto parece muito forte principalmente nas familias, cujas mães não trabalham além do ambiente doméstico. A palavra "mãe" traz em si uma conotação idealizada, uma imagem de segurança, de estabilidade. A mulher cresce aprendendo com a mãe e tentando seguir a sua imagem, porque é isso que é esperado pela sociedade. Nesse sentido, observamos neste estudo que há uma expectativa dos outros membros da família, avós, país e irmãos sobre como a mãe irá desempenhar o cuidado. Observamos também que em todos os sistemas familiares estudados, quando as mães eram jovens, as avós se mantiveram atentas ao que era explicado e fizeram perguntas.

O significado da experiência da doença molda o sofrimento como uma forma de sofrimento moral ou espiritual. A experiência da doença assume um significado no sofrimento porque a relação entre o corpo e o eu é mediada por símbolos culturais de ordem religiosa, moral ou espiritual (13). Nessa perspectiva, há uma necessidade de buscar as razões do sofrimento, que podem ser expressas como um castigo ou uma falha moral, nesse caso, uma falha moral no dever de ser mãe, uma "boa mãe".

Ao mesmo tempo em que o sentimento de culpa parece, de certa forma, tornar as mães mais atentas no que se refere ao cuidado (tentando ser uma "boa mãe"), pode também constituir uma barreira que dificultará mais ainda a compreensão da mãe sobre o cuidado e o ajuste no que se refere às mudanças corporais sofridas pelo seu filho.

Dessa forma, a família também está sofrendo não só por todas as mudanças que ocorrem diante de um acidente por queimaduras, como por exemplo, pela separação de um ente querido pela hospitalização, pelas mudanças funcionais e estruturais que o cliente poderá sofrer, pelos sucessivos procedimentos cirúrgicos, e por mudanças em aspectos econômicos do sistema familiar, mas também pela percepção de culpa. Portanto, os problemas que os familiares irão enfrentar precisam ser antecipados e é importante oferecer oportunidades para que essas pessoas abordem seus problemas e reflitam sobre eles, buscando ajuda dos profissionais de saúde para alcançar um equilíbrio. Nesse processo, os profissionais de saúde precisam considerar as 
perspectivas dos familiares e estar atentos para não criar mais conflitos morais ou religiosos.

\section{A participação da familia no processo de} cuidar da pessoa que sofreu queimaduras: dar apoio moral e fazer tudo o que estiver ao alcance

Nessa categoria, agrupamos os códigos em que os familiares se referiam a alguma forma de cuidado. Quatorze dos 25 familiares de clientes entrevistados falaram sobre a participação da família no cuidado, ressaltando algumas formas de cuidar: ajudar a pessoa a esquecer o problema; acalmar a pessoa, procurando tranqüilizá-la; dar apoio moral, psicológico, ou emocional, visando ajudar no enfrentamento das mudanças corporais; fazer tudo o que estiver ao alcance; fazer curativos; deixar tudo limpinho e ajudar a pessoa a se cuidar.

Os cuidados relacionados com os problemas decorrentes de alterações no estado emocional, em função das mudanças corporais, foram também apontados. Como forma de apoio psicológico ou emocional, os familiares afirmaram que estimularão o cliente a levar uma vida normal, ouvirão e conversarão com ele para que não se sinta inferior.

Eu vou apoiá-la em tudo o que ela precisar, posso ouvir, dar meu ombro para ela chorar... (familiar 4, irmã).

Procurar a ajuda que for possivel, seja onde for, é uma forma de ajuda expressa por alguns familiares. Assim, um pai afirmou que foi procurar o Dr Pitangui, profissional reconhecido mundialmente pelo seu trabalho como cirurgião plástico:

$$
\begin{aligned}
& \text { _...fui até procurar o } \mathrm{Dr} \text { Pitangui... } \\
& \text { (familiar 26, pai). }
\end{aligned}
$$

Dessa forma, os familiares transferem, pelo menos momentaneamente, o problema e minimizam a culpa ou diminuem o sentimento de impotência que estão sentindo, pois estão tentando fazer tudo o que podem.

Embora afirmem desconhecer os cuidados que os clientes necessitam, mencionaram estratégias que pensam em utilizar, como por exemplo: pedir ajuda a amigos ou parentes que tenham experiência, procurar um profissional (enfermeiro ou psicólogo) e aprender com os enfermeiros do hospital.

_Eu vou procurar ajuda de um psicólogo porque eu acho que ela vai precisar (familiar 4, irmã).

Além da ajuda do profissional, os familiares também disseram que procurarão ajuda com vizinhos, familiares com mais experiência e amigos. Em qualquer sociedade complexa, são identificados três tipos deâmbitos de assistência à saúde: o informal, o popular e o profissional (13). A assistência informal refere-se a automedicação, ao tratamento autoindicado, ou indicado por um parente, um vizinho ou um amigo. O âmbito de assistência popular refere-se à assistência praticada por curandeiros, e o profissional refere-se à praticada pelos profissionais, como psicólogos, enfermeiros, médicos, fisioterapeutas, entre outros. É possivel que ao procurar o vizinho, o amigo ou um parente, alguém com mais experiência, o familiar esteja procurando por alguém que focaliza no tratamento, as suas crenças, as suas expectativas, ou seja, que fala a sua lingua, que além de estar mais próximo fisicamente, está mais próximo do ponto de vista cultural. A partir dessa perspectiva, as pessoas que atuam no âmbito popular ou no informal podem estar oferecendo um alívio mais rápido e efetivo que no profissional.

Diante do sofrimento e do medo, uma outra ajuda que mencionaram é pedir a Deus:

\section{_Ai eu falei... Deus ajuda, e eu sonhei que ele tinha saído, quem sabe é isso, mas mesmo assim, eu fiquei com medo, falei ai meu Deus do céu, e se for outra coisa, seja o que Deus quiser:.. (Familiar 5, mãe).}

O catolicismo popular apresenta aspectos contraditórios para explicar que o sofrimento não deve ser questionado: primeiro porque o sofrimento é entendido como inerente à condição humana, e segundo porque é uma provação, um castigo pelos pecados praticados (23). No presente estudo, observamos sentimentos de resignação frente aos desígnios de Deus, e também a esperança de mudança pela ação de Deus e, ao mesmo tempo, o medo de não ser merecedor de uma "graça", de não ter seu pedido atendido.

Os familiares que afirmaram que participarão do processo de cuidar apontaram como estratégias: dar apoio psicológico (estimular positivamente o cliente, ajudar a aceitar e a levar uma vida normal, e ouvir), reorganizar a vida para atender ao cliente, fazer cuidados higiênicos, manter o ambiente limpo para evitar a infecção, fazer os procedimentos que forem necessários, como curativos, massagem e estimular o autocuidado. Entretanto, mesmo os familiares que identificaram alguma estratégia de participação relataram que será dificil conviver com a situação de ter um parente que sofreu uma queimadura.

Tema cultural - o estigma da queimadura e o processo de cuidar: o medo num mundo que só quem está dentro sabe o que é

O tema cultural identificado neste estudo foi "O estigma da queimadura e o processo de cuidar: o medo 
num mundo que só quem está dentro sabe o que é". O retorno ao convivio com as outras pessoas, sejam elas da família, pertencentes a grupos de trabalho ou de convivio social, provoca medo nos familiares e clientes.

Da mesma forma que ocorre com o câncer, como comparou a mãe de uma criança, a sequela da queimadura é estigmatizada, embora não seja considerada uma doença. "Estigma se refere às marcas que publicamente desgraçam uma pessoa" (24). A deformidade desfigurante, assim como as ações bizarras decorrentes de uma doença mental, são estigmatizantes porque quebram as convenções culturais sobre o que é aceitável em termos de aparência e de comportamento e ainda, evocam outras categorias culturais, a saber, o abominável, o feio, o alienígena ou o inumano ${ }^{(24)}$. Um indivíduo estigmatizado está desqualificado para uma aceitação social plena, é uma pessoa que tem uma fraqueza ou um defeito ou uma deficiência ao olhar da sociedade

(25). O estigma tem, muitas vezes, um significado religioso, em que a pessoa é considerada como má ou pecaminosa (24).

A religião, entendida aqui como um sistema de significados simbólicos, fornece aos homens uma base para interpretar os fatos em situações em que a realidade parece confrontá-los com o seus limites de poder humano para enfrentar a dor e o sofrimento, com a falta de orientação moral e com o inexplicável

(26). Surge então a pergunta por que eu?. Freqüentemente, os pais fazem perguntas como essas e outras como: por que com meu filho? Por que agora? Esses questionamentos também foram apresentados pelos familiares em nosso estudo. As respostas a essas questões são, muitas vezes, religiosas ou metafísicas. Alguns podem interpretar o acidente como uma punição ou como uma advertência de Deus, como um teste ou uma forma de aproximar a família (27).

O poder do estigma é tal que afeta as relações e pode levar a pessoa ao isolamento social (24). Nesse contexto, o cliente pode também sentir vergonha, não só pelo que significa o problema de saúde ou a marca da queimadura para si mesmo, mas em resposta a reações dos familiares e das outras pessoas.

\section{CONSIDERAÇÕES FINAIS}

Observou-se neste estudo que há todo um contexto cultural, um sistema de significados, em que as pessoas se relacionam que precisa ser considerado pelos profissionais de saúde. O tema cultural apresentado mostra que a perspectiva de cuidar de uma pessoa que sofreu uma queimadura gera alguns sentimentos e comportamentos apresentados pelos familiares que não favorecem esse processo. Essas situações, que compõem um sistema de significados culturais relacionados à queimadura, precisam ser identificadas e consideradas pelos enfermeiros no desenvolvimento dos programas educativos. A compreensão da cultura de um grupo, ou seja, dos sistemas de significados culturais, fornece subsídios para compreensão dessas pessoas. Conhecer a cultura de um grupo é importante não para apontar as diferenças, mas para compreender e aprender a lidar com elas. Nesse sentido, é importante que o profissional busque compreender a experiência da doença, para que no processo de ensino e aprendizagem, atue como facilitador da aprendizagem e não como aquele que julga que é o detentor do saber.

Com base nesses resultados e na literatura $(4,11)$, elaboramos um programa educativo para familiares de clientes que sofreram queimaduras. Esse programa tem permitido que os clientes e seus familiares planejem estratégias de mudanças e recebam informações que auxiliam nas mudanças de atitude e comportamentos.

\section{REFERÊNCIAS BIBLIOGRÁFICAS}

(1) Rossi LA, Barruffini RCP, Dalri MC, Braga EF, Carvalho EC. Las representaciones sociales de los familiares de pacientes quemados. Rev Invest Educ Enferm 1999; 17: 63-71.

(2) Davindson T, Bowden M, Tholen D, James M, Feller I. Social support and post-burn adjustment. Arch Phys Med Rehabil $1991 ; 62: 274-8$.

(3) Partridge J, Robinson E. Psychological and social aspects of burns. Burns 1995; 21: 453-7.

(4) Robinson E, Clarke A, Cooper C. The psychology of facial disfigurement. London: Changing Faces; 1997.

(5) Thompson R, Boyle D, Teel C, Wambach K, Cramer A. A qualitative analyses of family member needs and concerns in the population of patients with burns. J Burn Care Rehabil 1999; 20:487-96.

(6) Barnes A, Budd L. Family-centred burn care. Can Nurse 1999; 95:24-7.

(7) Giulliani CA, Perry GA. Factors to consider in the rehabilitation aspect of burn care. Phys Ther 1985; 65: 619-23.

(8) Harden NG, Luster SH. Rehabilitation considerations in the care of the acute burn patient. Crit Care Nurs Clin North Am 1991; 3:245-53.

(9) Blalock SJ, Bunker BJ, Moore JD, Foreman N, Walsh, JF. The impact of burn injury: a preliminary investigation. J Burn Care Rehabil 1992;13:487-92. 
(10) Bayley EW, Carrougher GJ, Marvin JA, Knighton J, Rutuan RL, Weber BF. Research priorities for burn nursing: rehabilitation, discharge planning, and follow-up care. J Burn Care Rehabil 1992; 13:471-6.

(11) Robinson CA. Nursing interventions with families: a demand or an invitation to change? J Adv Nurs 1994; 19: 897-904.

(12) D'Andrade R. Cultural Meaning systems In: Shweder RA, Levine RA Culture theory: essays on mind, self, and emotion. New York: Cambridge University Press; 1997. p 88-119.

(13) Kleinman A. Patients and healers in the context of culture: an exploration of the borderland between anthropology, medicine and Psychiatry. Los Angeles: University of California Press; 1984.

(14)Hornby AS. Oxford. advanced learner's dictionary of current. English. Oxford: Oxford University Press; 2000.

(15) Alves PC. A experiência da enfermidade: considerações teóricas. Cad Saúde Publica 1993; 9:263-71.

(16) Villares CC, Redko CP, Mari JJ. Concepções de doença por familiares de pacientes com diagnóstico de esquizofrenia. Rev Bras Psiquiatr 1999;21:36-47.

(17)Uchôa E, Vidal JM. Antropologia médica: elementos conceituais para uma abordagem da saúde e da doença. Cad Saúde Publica 1994;10: 497-504.

(18) Miles MB, Huberman AM. Qualitative data analysis: an expanded sourcebook. 2 ed London: Sage Publications; 1994.

(19) Oliveira MLS, Bastos AC S. Práticas de atenção à saúde no contexto familiar: um estudo comparativo de casos. Psicol Reflexão Crit 2000; 13:1-15.
(20) Lupton D. Medicine as a culture: Illness, disease and body in western societies. London: Sage Publications; 2000.

(21) Wright LM, Leahey M. Nurses and families A guide to family assessment and intervention. 2 ed. Philadelphia: FA Davis; 1994.

(22) Rosaldo MZ. Toward an anthropology of self and feeling In: Shweder RA, Levine RA. Culture theory: essays on mind, self, and emotion. New York: Cambridge University Press; 1997

(23) Zaluar A. Milagre e castigo divino. In: Religião e sociedade. Rio de Janeiro: Tempo e Presença; 1980.

(24) Kleinman A. The illness narratives: suffering, healing e the human condition. Los Angeles: Basic Books; 1988.

(25) Goffman E. Estigma: notas sobre a manipulação da identidade deteriorada. 4 ed. Rio de Janeiro: Zahar; 1982

(26) Geertz C. A interpretação das culturas. Rio de Janeiro: Zahar; 1978.

(27) Knudson-Cooper MS. Adjustment to visible stigma: the case of the severely burned Soc. Sci. \& Med. 1981; 15B: $1-44$

\section{Agradecimentos:}

Para realização deste estudo contamos com o apoio da FAPESP - Fundação de Amparo à Pesquisa do Estado de São Paulo e do CNPq - Conselho Nacional de Desenvolvimento Científico e Tecnológico. 